\title{
Quality of Life Questionnaire-Bronchiectasis: final psychometric analyses and determination of minimal important difference scores
}

\author{
Alexandra L Quittner, ${ }^{1}$ Anne E O'Donnell, ${ }^{2}$ Matthias A Salathe, ${ }^{3}$ Sandra A Lewis, ${ }^{4}$ \\ Xiaoming Li, ${ }^{4}$ A Bruce Montgomery, ${ }^{5}$ Thomas G O'Riordan, ${ }^{4}$ Alan F Barker ${ }^{6}$
}

- Additional material is published online only. To view please visit the journal online (http://dx.doi.org/10.1136/ thoraxjnl-2014-205918)

For numbered affiliations see end of article.

\section{Correspondence to} Dr Alexandra L Quittner, University of Miami, 5665 Ponce de Leon Blvd., Coral Gables, FL 33146, USA; AQuittner@Miami.edu

Received 20 June 2014 Revised 22 September 2014 Accepted 25 September 2014 Published Online First 16 October 2014

\section{ABSTRACT}

Background The Quality of Life-Bronchiectasis (QOL-B), a self-administered, patient-reported outcome measure assessing symptoms, functioning and health-related quality of life for patients with non-cystic fibrosis (CF) bronchiectasis, contains 37 items on 8 scales (Respiratory Symptoms, Physical, Role, Emotional and Social Functioning, Vitality, Health Perceptions and Treatment Burden).

Methods Psychometric analyses of QOL-B V.3.0 used data from two double-blind, multicentre, randomised, placebo-controlled, phase III trials of aztreonam for inhalation solution (AZLI) in 542 patients with non-CF bronchiectasis and Gram-negative endobronchial infection. Results Excellent internal consistency (Cronbach's $\alpha$ $\geq 0.70$ ) and 2-week test-retest reliability (intraclass correlation coefficients $\geq 0.72$ ) were demonstrated for each scale. Convergent validity with 6 min walk test was observed for Physical and Role Functioning scores. No floor or ceiling effects (baseline scores of 0 or 100) were found for the Respiratory Symptoms scale (primary endpoint of trials). Baseline Respiratory Symptoms scores discriminated between patients based on baseline $\mathrm{FEV}_{1} \%$ predicted in only one trial. The minimal important difference score for the Respiratory Symptoms scale was 8.0 points. AZLI did not show efficacy in the two phase III trials. QOL-B responsivity to treatment was assessed by examining changes from baseline QOL-B scores at study visits at which protocol-defined pulmonary exacerbations were reported. Mean Respiratory Symptoms scores decreased 14.0 and 14.2 points from baseline for placebo-treated and AZLI-treated patients with exacerbations, indicating that worsening respiratory symptoms were reflected in clinically meaningful changes in QOL-B scores.

Conclusions Previously established content validity, reliability and responsivity of the QOL-B are confirmed by this final validation study. The QOL-B is available for use in clinical trials and routine clinical practice.

\section{INTRODUCTION}

Bronchiectasis is a lung disease characterised by chronic cough and sputum production, often accompanied by airway bacterial infection. ${ }^{1-6}$ Treatments for non-cystic fibrosis (CF) bronchiectasis are limited and the assessment of new treatments is limited by lack of validated clinical trial endpoints. ${ }^{7}$ Unlike CF, large decreases in bacterial density in non-CF bronchiectasis placebo-controlled studies did not lead to improvements in clinical symptoms or $\mathrm{FEV}_{1},{ }^{8}$

\section{Key messages}

\section{What is the key question?}

- To compute the psychometric properties of the first disease-specific health-related quality of life measure for non-cystic fibrosis (CF) bronchiectasis.

\section{What is the bottom line?}

- The Quality of Life-Bronchiectasis (QOL-B) has demonstrated excellent psychometric properties in two large-scale clinical trials and minimal important difference values have been calculated for each scale to aid researchers and clinicians in interpreting QOL-B data; the measure is ready for research and clinical use.

\section{Why read on?}

- There is an unmet clinical need for approved therapies in non-CF bronchiectasis; however, these efforts have been hampered by the lack of reliable, disease-specific outcomes.

although improvement on the St George's Respiratory Questionnaire (SGRQ) was observed in exploratory analyses of treatment-adherent patients in a colistin study. ${ }^{9}$ Without reliable surrogates for clinical efficacy (e.g., $\mathrm{FEV}_{1}$ ), accurate measures of symptom frequency and severity are needed for bronchiectasis drug development. Furthermore, developing an endpoint assessing functioning of non-CF bronchiectasis patients in their daily lives would complement an exacerbation endpoint.

The Quality of Life-Bronchiectasis (QOL-B), a selfadministered patient-reported outcome (PRO) measure, was developed in response to the need for such new measurement tools. It assesses symptoms, functioning and health-related quality of life (HRQoL) for non-CF bronchiectasis patients and includes 37 items on 8 scales (Respiratory Symptoms, Physical, Role, Emotional and Social Functioning, Vitality, Health Perceptions and Treatment Burden). ${ }^{10} 11$ Development followed the procedures and analyses recommended by the Food and Drug Administration (FDA) guidance on PROs. ${ }^{12}$ Previously reported content validity, cognitive testing and psychometric analyses conducted on interim versions supported QOL-B concepts and items. ${ }^{10}$
To cite: Quittner $A L$,
O'Donnell $A E$, Salathe $M A$ et al. Thorax 2015;70 $12-20$. 
This manuscript presents psychometric analyses of QOL-B Version (V) 3.0 computed using data from two double-blind, multicentre, randomised, placebo-controlled, phase III trials of aztreonam for inhalation solution (AZLI) in patients with non-CF bronchiectasis and Gram-negative endobronchial infection. While these two studies did not demonstrate clinical efficacy, ${ }^{13}$ the use of a prespecified protocol-defined criteria for acute bronchiectasis exacerbations facilitated using the QOL-B for quantifying changes in respiratory symptoms during exacerbations. The minimal important difference (MID) scores for each scale were also estimated.

\section{METHODS}

\section{Study design}

QOL-B psychometric analyses presented herein used data from two phase III clinical trials: AIR-BX1 (47 sites; Australia, Canada and the USA; April 2011-March 2013; clinicaltrials. gov: NCT01313624) and AIR-BX2 (65 sites; Australia, Belgium, Canada, France, Germany, Italy, the Netherlands, Spain, UK and the USA; April 2011-July 2013; clinicaltrials. gov: NCT01314716). Both trials had the same design. The trial design, inclusion and exclusion criteria and results are described elsewhere. ${ }^{13}$ Briefly, patients received double-blind treatment with AZLI $75 \mathrm{mg}$ or placebo (1:1 randomisation; code generated by Gilead designee; randomisation occurred at baseline using an interactive voice/web response system) administered 3 times daily for 28 days, with each of 2 double-blind treatment courses followed by 28-day off-treatment. Procedures to generate QOL-B translations followed internationally accepted and regulatory guidelines, using formal backward and forward translation methodologies. ${ }^{12} 14 \quad 15$ Translations and cultural adaptations (e.g., using American English QOL-B in the UK) were tested with patients who were native speakers of the translated/ adapted language. A complex, multistep process ensured cultural equivalence and each new translation was piloted in the new language with $\geq 5$ patients with non-CF bronchiectasis.

Studies were conducted in accordance with principles of the Declaration of Helsinki, International Conference on Harmonisation guidelines and good clinical practice principles. Institutional Review Boards/Ethics Committees approved the study for each site. Patients provided written informed consent prior to study participation.

\section{Patients}

Inclusion/exclusion criteria are described elsewhere. ${ }^{13}$ Eligible patients ( $\geq 18$ years of age) had bronchiectasis confirmed by CT chest scan, a positive sputum culture for target Gram-negative organism(s) at screening, chronic sputum production on $\geq 4$ days/ week during prior 4 weeks and $\mathrm{FEV}_{1} \geq 20 \%$ predicted at screening. Target Gram-negative respiratory pathogens included species of Achromobacter, Burkholderia, Citrobacter, Enterobacter, Escherichia, Klebsiella, Moraxella, Proteus, Pseudomonas, Serratia and Stenotrophomonas. Patients with CF or with only Haemophilus influenzae respiratory infections were excluded.

\section{Study measures}

Three measures of clinical response were specified in the protocol and used to measure discriminant and/or convergent validity, including $\mathrm{FEV}_{1}$, the 6 min Walk Test $(6 \mathrm{MWT})^{16}$ and the Euro Quality of Life-5 Dimensions (EQ-5D). ${ }^{17}$

Spirometry was performed at each visit, after administration of a short acting inhaled bronchodilator.

The 6MWT, measuring distance walked in $6 \mathrm{~min}$, was administered at every visit. No MID has been reported for non-CF bronchiectasis. In patients with COPD, a change of $54-80 \mathrm{~m}$ is perceived as a small improvement/worsening in walking ability $^{18}$; another study suggests that a change of $10 \%$ from baseline is clinically important. ${ }^{19}$

The EQ-5D, a standardised self-reported measure of global health status, was administered at the beginning and at the end of each treatment course. Results for the EQ-5D visual analogue scale (VAS) are presented. General health states were assessed by responses on a vertical scale from 0 (worst imaginable) to 100 (best imaginable). No MID has been reported for non-CF bronchiectasis.

QOL-B V.3.0 was administered at every study visit; V.3.0 differs only very slightly from the final V.3.1 (an example was provided and a 'not applicable' category was added to 1 item on the V.3.1 Social Functioning scale). ${ }^{10} 20$ Each of the 37 items is scored from 1 to 4 , and each of the 8 scale scores is standardised on a $0-100$ point scale, with higher scores representing fewer symptoms or better functioning and HRQoL. A total score is not calculated. Scales contain between 3 and 9 items, thus changing 1 answer category will correspond to a change of 11.1 to 3.7 points.

The Global Rating of Change Questionnaire (GRCQ) V.2.2 (15 point Likert-like scale) and V.3.0 (7 point scale) were administered at day 14, immediately after the QOL-B. Each GRCQ item corresponded to 1 of the 8 QOL-B scales and patients responded to each GRCQ item using a VAS. Changes from baseline at day 14 were evaluated from -7 (a very great deal worse) to +7 (a very great deal better) for items on GRCQ V.2.2 and from -3 (a great deal worse) to +3 (a great deal better) for GRCQ V.3.0 (the Respiratory Symptoms GRCQ V.2.2 and V.3.0 are provided in online supplementary figure S1). Zero indicated no change. A switch from the 15-point to the 7-point GRCQ scoring system was made following a suggestion from a regulatory agency while these two trials were ongoing. Scores are presented based on GRCQ V.3.0. GRCQ V.2.2 scores ( -7 to 7 ) were converted to the V.3.0 scale ( -3 to 3 ) by multiplying by $3 / 7$.

Protocol-defined exacerbations were defined as acute worsening of respiratory disease meeting $\geq 3$ major criteria (increased sputum production, sputum discolouration, dyspnoea and cough) or 2 major criteria and $\geq 2$ minor criteria (fever $>38^{\circ} \mathrm{C}$ at a clinic visit, increased malaise or fatigue, $\mathrm{FEV}_{1}$ [L] or FVC decreased $>10 \%$ from baseline and new/increased haemoptysis). ${ }^{13}$

\section{Analyses}

Statistical analyses were performed with SAS V.9.2 (SAS Institute, Cary, North Carolina, USA). Internal consistency was measured using Cronbach's $\alpha^{21}$ Test score reproducibility over 14 days (i.e., test-retest reliability) was calculated with intraclass correlation coefficients (ICCs). ${ }^{22}$ Spearman's correlations were calculated. The protocols specified that AIR-BX1 and AIR-BX2 study results were to be analysed separately; pooled data were used for some exploratory analyses. MIDs were calculated for each scale. ${ }^{23-25}$ For patients in the minimal change GRCQ category $(>0.5-1.5$ improvement or worsening from baseline on the 3-point scale), their mean change from baseline QOL-B scores at day 14 was the anchor-based MID. Two distribution-based MIDs were calculated: 1/2 SD of the change from baseline QOL-B scores at day 14 and 1 SE of measurement (SEM) for baseline scores $(\mathrm{SEM}=\mathrm{SD} \sqrt{ }(1-\alpha))$. The 6 MIDs (3 methods across 2 studies) were averaged and rounded to the nearest integer to generate a final MID for each scale.

\section{RESULTS}

In AIR-BX1, 266 patients were randomised and treated (AZLI: $\mathrm{n}=134$; placebo: $\mathrm{n}=132$ ). In AIR-BX2, 274 patients were randomised and 272 were treated (AZLI: 135; placebo: 137). Demographic and baseline characteristics were comparable for 
both treatment arms, except for a significant difference $(p=0.017)$ in the distribution of patients within $\mathrm{FEV}_{1} \%$ predicted categories in AIR-BX1, with 38.8\% of AZLI-arm patients having baseline $\mathrm{FEV}_{1}<50 \%$ predicted compared with $25.0 \%$ of placebo-arm patients (table 1). Additional baseline characteristics are described elsewhere. ${ }^{13}$

\section{Floor and ceiling effects}

Floor and ceiling effects were assessed by examining baseline QOL-B scores, to determine whether patients had room to both improve and worsen on each scale (table 2). Floor effects were not observed. One patient $(0.4 \%)$ in each study had a Respiratory Symptoms score of 0 and $\leq 5.1 \%$ of patients on each study had scores of 0 on any of the other scales. Ceiling effects (baseline scores of 100) were not observed for the Respiratory Symptoms scale. Ceiling effects were observed on the Emotional Functioning $(24.1 \%$ and $22.3 \%$ of patients on AIR-BX1 and AIR-BX2, respectively), and on the Treatment Burden scale (13.4\% and $11.3 \%$ of patients).

\section{Internal consistency}

Internal consistency of QOL-B scales was assessed with Cronbach's $\alpha$ (table 3 ). Values were $\geq 0.70$ for each scale, showing good reliability (i.e., items on each scale correlated with each other, forming a unitary construct). ${ }^{21}$

\section{Discriminant validity}

Mean baseline QOL-B scores were compared for patients differing by other health status indicators (table 4). The QOL-B Physical Functioning scale discriminated between patients on the basis of $\mathrm{FEV}_{1} \%$ predicted; in both studies, mean baseline Physical Functioning scores were approximately 20-30 points larger for patients with baseline $\mathrm{FEV}_{1} \geq 80 \%$ predicted compared with $<50 \%$ predicted. Discrimination was less robust for Respiratory Symptoms, Vitality, Role Functioning and Health Perception scales; mean scores at baseline were approximately 10 points larger for patients with baseline $\mathrm{FEV}_{1} \geq 80 \%$ predicted compared with $<50 \%$ predicted only in AIR-BX2. Statistically significant discrimination on the basis of median

Table 1 Demographic and baseline characteristics

\begin{tabular}{|c|c|c|c|c|c|c|c|}
\hline & & \multicolumn{3}{|l|}{ AIR-BX1 } & \multicolumn{3}{|l|}{ AIR-BX2 } \\
\hline & & $\begin{array}{l}\text { AZLI } \\
(\mathrm{N}=134)\end{array}$ & $\begin{array}{l}\text { Placebo } \\
(\mathrm{N}=132)\end{array}$ & p Value* & $\begin{array}{l}\text { AZLI } \\
(\mathrm{N}=136)\end{array}$ & $\begin{array}{l}\text { Placebo } \\
(\mathrm{N}=138)\end{array}$ & p Value* \\
\hline Age, years; mean (SD) & & $64.2(12.9)$ & $64.9(12.1)$ & 0.65 & $63.3(14.2)$ & $62.7(13.3)$ & 0.75 \\
\hline Age, years; range & & $23-83$ & $20-88$ & & $22-85$ & $18-87$ & \\
\hline $\mathrm{FEV}_{1} \%$ predicted, mean (SD) & & $60.4(22.6)$ & $64.5(18.7)$ & 0.11 & $63.8(19.5)$ & $63.4(21.6)$ & 0.88 \\
\hline Range & & 18.1-109.4 & 20.6-114.1 & & 22.7-115.5 & 19.5-115.3 & \\
\hline$<50 \%$ predicted, $\mathrm{n}(\%)$ & & $52(38.8)$ & $33(25.0)$ & & $37(27.2)$ & $42(30.4)$ & \\
\hline$\geq 50$ to $<80 \%$ predicted, $\mathrm{n}(\%)$ & & 49 (36.6) & $70(53.0)$ & 0.017 & $72(52.9)$ & $61(44.2)$ & 0.32 \\
\hline$\geq 80 \%$ predicted, $\mathrm{n}(\%)$ & & $33(24.6)$ & $29(22.0)$ & & 27 (19.9) & $35(25.4)$ & \\
\hline BMI, mean (SD) & & $25.0(5.1)$ & $24.7(4.9)$ & 0.66 & $23.9(5.0)$ & $24.7(6.0)$ & 0.25 \\
\hline Female, n (\%) & & $84(62.7)$ & $97(73.5)$ & 0.07 & $89(65.4)$ & $101(73.2)$ & 0.19 \\
\hline Target Gram-negative pathogen at baseline, $\dagger \mathrm{n}(\%)$ & & $131(97.8)$ & $129(97.7)$ & 1.0 & $135(100) \ddagger$ & $136(99.3) \ddagger$ & 0.62 \\
\hline 6MWT, metres; mean (SD) & & $421(119.3)$ & $426(118.5)$ & 0.74 & $423(127.5)$ & $428(120.8)$ & 0.75 \\
\hline EQ-5D visual analogue score at baseline, $\S$ mean (SD) & & $66.1(18.1)$ & $69.9(16.5)$ & 0.08 & $65.7(16.0)$ & $68.0(14.9)$ & 0.23 \\
\hline \multicolumn{8}{|l|}{ QOL-B V.3.0 Scales: scores at baseline; mean (SD), range } \\
\hline & $\begin{array}{l}\text { Points for change of } 1 \\
\text { answer category for } 1 \\
\text { item }\end{array}$ & & & & & & \\
\hline Respiratory Symptoms & 3.7 & 55.0 (19.3) & 55.5 (19.3) & 0.82 & 56.2 (18.0) & 57.4 (18.1) & 0.60 \\
\hline Physical Functioning & 6.7 & $\begin{array}{l}51.6(30.5) \\
0-100\end{array}$ & $\begin{array}{l}55.7(29.7) \\
0-100\end{array}$ & 0.27 & $\begin{array}{l}49.7(30.1) \\
0-100\end{array}$ & $\begin{array}{l}47.9(28.8) \\
0-100\end{array}$ & 0.61 \\
\hline Vitality & 11.1 & $\begin{array}{l}50.4(20.6) \\
0-100\end{array}$ & $\begin{array}{l}49.5(21.4) \\
0-100\end{array}$ & 0.72 & $\begin{array}{l}50.6(23.0) \\
0-100\end{array}$ & $\begin{array}{l}49.3(19.3) \\
0-100\end{array}$ & 0.60 \\
\hline Role Functioning & 6.7 & $\begin{array}{l}62.9(25.0) \\
0-100\end{array}$ & $\begin{array}{l}64.7(24.4) \\
13.3-100\end{array}$ & 0.53 & $\begin{array}{l}61.3(26.6) \\
0-100\end{array}$ & $\begin{array}{l}63.3(26.5) \\
0-100\end{array}$ & 0.51 \\
\hline Health Perceptions & 8.3 & $\begin{array}{l}44.6(20.6) \\
0-100\end{array}$ & $\begin{array}{l}47.3(22.1) \\
0-91.7\end{array}$ & 0.30 & $\begin{array}{l}43.9(20.1) \\
0-91.7\end{array}$ & $\begin{array}{l}42.9(20.5) \\
0-91.7\end{array}$ & 0.67 \\
\hline Emotional Functioning & 8.3 & $\begin{array}{l}78.3(20.4) \\
8.3-100\end{array}$ & $\begin{array}{l}78.4(20.1) \\
25.0-100\end{array}$ & 0.98 & $\begin{array}{l}77.5(22.4) \\
0-100\end{array}$ & $\begin{array}{l}76.9(19.2) \\
8.3-100\end{array}$ & 0.80 \\
\hline Social Functioning & 8.3 & $\begin{array}{l}54.8(26.0) \\
0-100\end{array}$ & $\begin{array}{l}51.3(27.2) \\
0-100\end{array}$ & 0.28 & $\begin{array}{l}55.3(27.2) \\
0-100\end{array}$ & $\begin{array}{l}54.6(27.4) \\
0-100\end{array}$ & 0.83 \\
\hline Treatment Burden** & 11.1 & $\begin{array}{l}65.6(24.0) \\
0-100\end{array}$ & $\begin{array}{l}66.8(24.7) \\
0-100\end{array}$ & 0.70 & $\begin{array}{l}63.2(23.8) \\
0-100\end{array}$ & $\begin{array}{l}66.7(23.7) \\
0-100\end{array}$ & 0.25 \\
\hline
\end{tabular}


Table 2 Floor and ceiling effects: QOL-B scores at baseline

\begin{tabular}{|c|c|c|c|c|}
\hline \multirow[b]{2}{*}{ QOL-B V.3.0 scale } & \multicolumn{2}{|c|}{ AIR-BX1 (N=266) } & \multicolumn{2}{|c|}{ AIR-BX2 (N=274) } \\
\hline & $\begin{array}{l}\text { Floor effects* } \\
\text { (score=0) } \\
\text { n (\%) }\end{array}$ & $\begin{array}{l}\text { Ceiling effects* } \\
\text { (score=100) } \\
\text { n (\%) }\end{array}$ & $\begin{array}{l}\text { Floor effects* } \\
(\text { score=0) } \\
n(\%)\end{array}$ & $\begin{array}{l}\text { Ceiling effects* } \\
\text { (score=100) } \\
\text { n (\%) }\end{array}$ \\
\hline Respiratory Symptoms & $1(0.4)$ & $0(0)$ & $1(0.4)$ & $0(0)$ \\
\hline Physical Functioning & $8(3.0)$ & $21(7.9)$ & $12(4.4)$ & $16(5.8)$ \\
\hline Vitality & $8(3.0)$ & $5(1.9)$ & $7(2.6)$ & $4(1.5)$ \\
\hline Role Functioning & $1(0.4)$ & $21(7.9)$ & $4(1.5)$ & $20(7.3)$ \\
\hline Health Perceptions & $3(1.1)$ & $1(0.4)$ & $4(1.5)$ & $0(0)$ \\
\hline Emotional Functioning & $0(0)$ & $64(24.1)$ & $1(0.4)$ & $61(22.3)$ \\
\hline Social Functioning & $10(3.8)$ & $11(4.1)$ & $14(5.1)$ & $9(3.3)$ \\
\hline Treatment Burdent & $2(0.8)$ & $33(13.4)$ & $3(1.2)$ & $28(11.3)$ \\
\hline
\end{tabular}

baseline 6MWT results was observed in both studies for Physical Functioning, Vitality, Role Functioning and Health Perception scores, and only in AIR-BX2 for Respiratory Symptoms and Emotional Functioning scores. Some of the statistically significant differences observed for 6MWT categories $(\mathrm{p}<0.05)$ were smaller than the MID values for these scales (see table 7) and thus were not considered clinically meaningful.

\section{Convergent validity}

Correlations between baseline QOL-B scores and other health status indicators are summarised (table 5). Moderate correlations were observed for baseline QOL-B Physical Functioning scores (AIR-BX2 only) and baseline $\mathrm{FEV}_{1} \%$ predicted, with weak or no correlations observed for other baseline QOL-B scores and $\mathrm{FEV}_{1} \%$ predicted. Moderate correlations were observed for Physical Functioning and Role Functioning scores and 6MWT results, with weak or no correlations observed for other scales. Moderate to strong correlations were observed between baseline QOL-B scores and most baseline EQ-5D VAS scores.

\section{Test-retest reliability}

QOL-B test-retest reliability was assessed by ICC values (table 6). Values were $\geq 0.70$ for each scale, indicating good score reproducibility over the 14 -day interval. ${ }^{22}$

Table 3 Internal consistency of QOL-B scales

\begin{tabular}{|c|c|c|c|c|}
\hline \multirow[b]{2}{*}{ QOL-B V.3.0 scale } & \multicolumn{2}{|c|}{$\begin{array}{l}\text { AIR-BX1 } \\
(\mathrm{N}=266)\end{array}$} & \multicolumn{2}{|c|}{$\begin{array}{l}\text { AIR-BX2 } \\
(\mathrm{N}=274)\end{array}$} \\
\hline & $n^{*}$ & Cronbach's $\alpha$ & $n^{*}$ & Cronbach's $\alpha$ \\
\hline Respiratory Symptoms & 246 & 0.84 & 254 & 0.79 \\
\hline Physical Functioning & 260 & 0.92 & 267 & 0.91 \\
\hline Vitality & 264 & 0.77 & 271 & 0.70 \\
\hline Role Functioning & 253 & 0.83 & 255 & 0.86 \\
\hline Health Perceptions & 260 & 0.79 & 265 & 0.75 \\
\hline Emotional Functioning & 262 & 0.84 & 269 & 0.82 \\
\hline Social Functioning & 253 & 0.78 & 259 & 0.76 \\
\hline Treatment Burdent & 233 & 0.79 & 232 & 0.77 \\
\hline $\begin{array}{l}{ }^{*} \mathrm{Q} O L-B \text { responses at ba } \\
\text { table. } \\
\text { †Patients who were not } \\
\text { the Treatment Burden } s \\
\text { QOL-B, Quality of Life-B }\end{array}$ & $\begin{array}{l}\text { ne (da } \\
\text { eiving } \\
\text { chiecta }\end{array}$ & $\begin{array}{l}\text { were used for the } \\
\text { tment for bronchi }\end{array}$ & $\begin{array}{l}\text { alyses } \\
\text { sis wer }\end{array}$ & $\begin{array}{l}\text { ented in this } \\
\text { Istructed to skip }\end{array}$ \\
\hline
\end{tabular}

\section{MID values}

Changes from baseline QOL-B scores at day 14 were categorised by GRCQ responses. QOL-B scores were grouped for patients whose GRCQ scores indicated 'no change' or 'minimal,' 'moderate' or 'large change' from baseline to day 14. Each change from baseline category included improving and worsening scores. Data for the Respiratory Symptoms scale are presented (see online supplementary table S1). Mean change on the QOL-B scale for patients in the 'minimal change' GRCQ category was the anchor-based MID; values for the Respiratory Symptoms scale were 6.7 (AIR-BX1) and 11.4 (AIR-BX2) points (table 7). MIDs derived from $1 / 2$ SD of baseline scores were 8.0 (AIR-BX1) and 7.7 (AIR-BX2) points for the Respiratory Symptoms scale and values derived from the SEM of baseline scores were 7.7 (AIR-BX1) and 8.2 (AIR-BX2) points. Averaging these 6 MID estimates generated a final MID of 8.0 points for the Respiratory Symptoms scale.

\section{Responsivity to treatment or change in health status}

Clinically significant changes from baseline QOL-B Respiratory Symptoms scores were not observed after 14 days of AZLI or placebo treatment, because none of the mean changes exceeded the 8.0 point MID (see online supplementary table S2). Changes in $\mathrm{FEV}_{1}$ and $6 \mathrm{MWT}$ were also comparable between arms, as were changes on other QOL-B scales. In contrast, larger decreases from baseline sputum bacterial density after treatment were observed for the AZLI arm compared with placebo.

Because AZLI did not show clinically significant efficacy in the two phase III trials, an exploratory analysis was performed using change from baseline QOL-B Respiratory Symptoms scores for patients with a protocol-defined exacerbation reported at a study visit at which the QOL-B was also administered. These exacerbations occurred 6 days to approximately 4 months after baseline. Mean (SD) change from baseline QOL-B Respiratory Symptoms score was -14.2 (16.5) points for the 30 AZLI-treated patients with a protocol-defined exacerbation recorded at a study visit for which QOL-B scores were available (range: -50.5 to +18.5 points; figure $1 \mathrm{~A}$ ). Mean (SD) change from baseline was -14.0 (16.7) points for the corresponding 30 placebo-treated patients (range: -66.7 to +11.1 points; figure 1B). These mean values both exceeded the -8.0-point MID and were thus considered to represent clinically relevant worsening of respiratory symptoms in these study populations. 
Table 4 Discrimination of QOL-B scores by other indices of health status

\begin{tabular}{|c|c|c|c|c|c|c|c|c|}
\hline \multirow[b]{3}{*}{ QOL-B scale } & \multicolumn{4}{|l|}{ AIR-BX1 } & \multicolumn{4}{|l|}{ AIR-BX2 } \\
\hline & \multicolumn{8}{|c|}{ Mean (SD) QOL-B scores at baseline for patients with baseline FEV 1} \\
\hline & $\begin{array}{l}<50 \% \\
\text { predicted } \\
(\mathrm{N}=85)\end{array}$ & $\begin{array}{l}\geq 50 \text { to }<80 \% \\
\text { predicted ( } N=119)\end{array}$ & $\begin{array}{l}\geq 80 \% \\
\text { predicted } \\
(\mathrm{N}=62)\end{array}$ & p Value* & $\begin{array}{l}<50 \% \\
\text { predicted } \\
(\mathrm{N}=79)\end{array}$ & $\begin{array}{l}\geq 50 \text { to }<80 \% \\
\text { predicted }(\mathrm{N}=133)\end{array}$ & $\begin{array}{l}\geq 80 \% \\
\text { predicted } \\
(\mathrm{N}=62)\end{array}$ & p Value* \\
\hline $\begin{array}{l}\text { Respiratory } \\
\text { Symptoms }\end{array}$ & $53.4(18.7)$ & $54.8(19.3)$ & $58.5(19.9)$ & 0.27 & $51.7(17.5)$ & $57.6(18.3)$ & $61.6(16.7)$ & 0.004 \\
\hline $\begin{array}{l}\text { Physical } \\
\text { Functioning }\end{array}$ & $44.9(30.6)$ & $54.1(28.6)$ & $64.8(28.9)$ & $<0.001$ & $35.5(25.0)$ & $49.6(29.0)$ & $63.8(28.0)$ & $<0.001$ \\
\hline Vitality & $51.2(19.7)$ & $49.0(21.9)$ & $50.1(21.0)$ & 0.77 & $47.0(20.1)$ & 49.1 (21.5) & $55.5(21.1)$ & 0.050 \\
\hline $\begin{array}{l}\text { Role } \\
\text { Functioning }\end{array}$ & $63.7(25.1)$ & $62.8(23.7)$ & $65.8(26.2)$ & 0.74 & $54.5(26.8)$ & $64.4(25.5)$ & $67.9(26.3)$ & 0.005 \\
\hline $\begin{array}{l}\text { Health } \\
\text { Perceptions }\end{array}$ & $44.7(20.8)$ & $45.5(21.1)$ & $48.6(22.6)$ & 0.52 & $40.4(18.8)$ & $42.5(21.4)$ & 49.1 (18.7) & 0.030 \\
\hline $\begin{array}{l}\text { Emotional } \\
\text { Functioning }\end{array}$ & $79.0(21.0)$ & 78.5 (19.9) & $77.3(20.1)$ & 0.88 & $76.2(21.1)$ & $77.2(21.4)$ & 78.4 (19.5) & 0.82 \\
\hline $\begin{array}{l}\text { Social } \\
\text { Functioning }\end{array}$ & $57.1(25.4)$ & $50.5(26.6)$ & $52.4(28.0)$ & 0.22 & $53.3(28.1)$ & $55.1(27.9)$ & $56.6(25.0)$ & 0.77 \\
\hline $\begin{array}{l}\text { Treatment } \\
\text { Burdent }\end{array}$ & $65.0(24.6)$ & $68.5(24.4)$ & $63.1(23.6)$ & 0.36 & $62.6(23.5)$ & $67.2(23.3)$ & $63.0(24.9)$ & 0.34 \\
\hline
\end{tabular}

\begin{tabular}{|c|c|c|c|c|c|c|}
\hline \multirow[b]{3}{*}{ QOL-B scale } & \multicolumn{3}{|l|}{ AIR-BX1 } & \multicolumn{3}{|l|}{ AIR-BX2 } \\
\hline & \multicolumn{6}{|c|}{ Mean (SD) QOL-B scores at baseline for patients with baseline 6MWT: } \\
\hline & $\begin{array}{l}\text { Below median } \neq \\
(\mathrm{N}=128)\end{array}$ & $\begin{array}{l}\text { Above median } \neq \\
(\mathrm{N}=138)\end{array}$ & p Value* & $\begin{array}{l}\text { Below medianः } \\
(\mathrm{N}=138)\end{array}$ & $\begin{array}{l}\text { Above median } \neq \\
(\mathrm{N}=136)\end{array}$ & p Value* \\
\hline Respiratory Symptoms & $53.6(19.7)$ & $56.7(18.8)$ & 0.20 & $52.8(18.7)$ & $60.7(16.5)$ & $<0.001 \S$ \\
\hline Physical Functioning & $42.0(29.7)$ & $64.5(26.2)$ & $<0.001$ & $37.5(26.4)$ & $59.9(28.0)$ & $<0.001$ \\
\hline Vitality & $46.1(20.5)$ & $53.5(20.9)$ & $0.004 \S$ & $44.9(19.2)$ & $55.0(21.9)$ & $<0.001$ \\
\hline Role Functioning & $57.9(25.0)$ & $69.2(23.2)$ & $<0.001$ & $54.8(26.4)$ & $69.7(24.5)$ & $<0.001$ \\
\hline Health Perceptions & $42.1(20.7)$ & $49.6(21.3)$ & $0.004 \S$ & $40.2(19.6)$ & $46.5(20.5)$ & $0.009 \S$ \\
\hline Emotional Functioning & $77.5(20.5)$ & $79.2(20.0)$ & 0.49 & $74.3(21.5)$ & $80.0(19.9)$ & $0.024 \S$ \\
\hline Social Functioning & $52.1(27.7)$ & $53.9(25.7)$ & 0.58 & $53.8(28.1)$ & $56.0(26.5)$ & 0.52 \\
\hline Treatment Burdenๆ & $64.5(24.3)$ & $67.8(24.3)$ & 0.29 & $65.2(24.7)$ & $64.7(22.9)$ & 0.87 \\
\hline
\end{tabular}

${ }^{*} p$ Value is from an ANOVA model with the $\mathrm{FEV}_{1} \%$ predicted or $6 \mathrm{MWT}$ category as a fixed effect. Note: patients were not randomised by these categories at baseline.

tPatients who were not receiving treatment for bronchiectasis were instructed to skip the Treatment Burden scale; data available for 82,112 and 53 patients in AIR-BX1 and 73, 122 and 52 patients in AIR-BX2.

¥Median 6MWT was 427 metres (range 61-761) for AIR-BX1 and 436 metres (range 18-704) for AIR-BX2.

§The difference between responses below and above the median baseline 6MWT was statistically significant $(p<0.05)$ but was less than the MID for that scale (table 7 ) and thus was not considered clinically significant.

\Patients who were not receiving treatment for bronchiectasis were instructed to skip the Treatment Burden scale; data available for 126 and 121 patients in AIR-BX1 and 125 and 122 patients in AIR-BX2.

6MWT, 6 min walk test; MID, minimal important difference; QOL-B, Quality of Life-Bronchiectasis; ANOVA, analysis of variance.

\section{DISCUSSION}

Results of psychometric analyses of QOL-B V.3.0 data from 542 patients in two placebo-controlled AZLI trials support psychometric analyses reported for a preliminary version of the QOL-B (V.2.0), which included data from 89 patients in an open-label AZLI study. ${ }^{10}$ For QOL-B V.3.0, adequate internal consistency and test-retest reliability were demonstrated for all 8 scales. For the Respiratory Symptom scale, the primary endpoint of the two phase III trials, floor and ceiling effects were not observed. Analyses of discriminant validity on the basis of baseline $\mathrm{FEV}_{1} \%$ predicted values indicated that mean baseline Respiratory Symptoms scores were approximately 10 points larger (indicating fewer symptoms) for AIR-BX2 patients with baseline $\mathrm{FEV}_{1} \geq 80 \%$ predicted compared with $<50 \%$ predicted, but no statistically significant discrimination was observed in AIR-BX1. As was observed in the previous validation study of QOL-B V.2.0, ${ }^{10}$ the Physical Functioning scale discriminated well between levels of disease severity based on lung function measurements, with a statistically significant $\geq 20$-point spread for patients differing by baseline lung function. This discriminant validity, both the $\sim 10$-point spread in Respiratory Symptoms scores for AIR-BX2 and the $\geq 20$-point spread in Physical Functioning scores for both studies, is larger than the corresponding MID values ( 8 and 10 points, respectively) and thus are also considered clinically meaningful. However, the lack of consistent significant discrimination for QOL-B Respiratory Symptoms scores and $\mathrm{FEV}_{1} \%$ predicted agrees with results from prior studies, in which $\mathrm{FEV}_{1}$ was not strongly associated with decreases in airway bacteria after treatment or with better health status. ${ }^{8} 2627$

In the absence of demonstrable efficacy in the two phase III trials, responsivity to treatment was assessed for the QOL-B Respiratory Symptoms scale by examining mean changes from baseline for patients with a protocol-defined pulmonary exacerbation at a study visit at which the QOL-B had been administered. Mean scores decreased 14.2 and 14.0 points from baseline for AZLI-treated and placebo-treated patients with exacerbations, respectively, indicating that the patients' 
Table 5 Convergent validity: correlation between baseline QOL-B scores and other measures of health status

\begin{tabular}{|c|c|c|c|c|c|c|}
\hline \multirow[b]{3}{*}{ QOL-B scale } & \multicolumn{6}{|c|}{ Correlations of baseline scores on QOL-B scales with other measures of health status } \\
\hline & \multicolumn{2}{|c|}{$\mathrm{FEV}_{1} \%$ predicted } & \multicolumn{2}{|l|}{ 6MWT } & \multicolumn{2}{|c|}{ EQ-5D VAS } \\
\hline & $\begin{array}{l}\text { AIR-BX1 } \\
(\mathrm{N}=266)\end{array}$ & $\begin{array}{l}\text { AIR-BX2 } \\
(\mathrm{N}=274)\end{array}$ & $\begin{array}{l}\text { AIR-BX1 } \\
(\mathrm{N}=266)\end{array}$ & $\begin{array}{l}\text { AIR-BX2 } \\
(\mathrm{N}=274)\end{array}$ & $\begin{array}{l}\text { AIR-BX1 } \\
(\mathrm{N}=266)\end{array}$ & $\begin{array}{l}\text { AIR-BX2 } \\
(\mathrm{N}=274)\end{array}$ \\
\hline \multicolumn{7}{|c|}{ Respiratory Symptoms } \\
\hline & $\begin{array}{l}0.118 \\
(n=266) \\
p=0.054\end{array}$ & $\begin{array}{l}0.185 \\
(n=274) \\
p=0.002\end{array}$ & $\begin{array}{l}0.170 \\
(n=266) \\
p=0.005\end{array}$ & $\begin{array}{l}0.268 \\
(n=274) \\
p<0.001\end{array}$ & $\begin{array}{l}0.512 \\
(n=262) \\
p<0.001\end{array}$ & $\begin{array}{l}0.519 \\
(n=267) \\
p<0.001\end{array}$ \\
\hline \multicolumn{7}{|c|}{ Physical Functioning } \\
\hline & $\begin{array}{l}0.273 \\
(n=266) \\
p<0.001\end{array}$ & $\begin{array}{l}0.364 \\
(n=274) \\
p<0.001\end{array}$ & $\begin{array}{l}0.526 \\
(n=266) \\
p<0.001\end{array}$ & $\begin{array}{l}0.472 \\
(n=274) \\
p<0.001\end{array}$ & $\begin{array}{l}0.568 \\
(n=262) \\
p<0.001\end{array}$ & $\begin{array}{l}0.633 \\
(n=267) \\
p<0.001\end{array}$ \\
\hline \multicolumn{7}{|l|}{ Vitality } \\
\hline & $\begin{array}{l}0.011 \\
(n=266) \\
p=0.86\end{array}$ & $\begin{array}{l}0.115 \\
(n=274) \\
p=0.06\end{array}$ & $\begin{array}{l}0.294 \\
(n=266) \\
p<0.001\end{array}$ & $\begin{array}{l}0.267 \\
(n=274) \\
p<0.001\end{array}$ & $\begin{array}{l}0.546 \\
(n=262) \\
p<0.001\end{array}$ & $\begin{array}{l}0.631 \\
(n=267) \\
p<0.001\end{array}$ \\
\hline \multicolumn{7}{|c|}{ Role Functioning } \\
\hline & $\begin{array}{l}0.075 \\
(n=266) \\
p=0.22\end{array}$ & $\begin{array}{l}0.218 \\
(n=274) \\
p<0.001\end{array}$ & $\begin{array}{l}0.364 \\
(n=266) \\
p<0.001\end{array}$ & $\begin{array}{l}0.347 \\
(n=274) \\
p<0.001\end{array}$ & $\begin{array}{l}0.621 \\
(n=262) \\
p<0.001\end{array}$ & $\begin{array}{l}0.663 \\
(n=267) \\
p<0.001\end{array}$ \\
\hline \multicolumn{7}{|c|}{ Health Perceptions } \\
\hline & $\begin{array}{l}0.090 \\
(n=266) \\
p=0.14\end{array}$ & $\begin{array}{l}0.145 \\
(n=274) \\
p=0.016\end{array}$ & $\begin{array}{l}0.279 \\
(n=266) \\
p<0.001\end{array}$ & $\begin{array}{l}0.195 \\
(n=274) \\
p=0.001\end{array}$ & $\begin{array}{l}0.662 \\
(n=262) \\
p<0.001\end{array}$ & $\begin{array}{l}0.640 \\
(n=267) \\
p<0.001\end{array}$ \\
\hline \multicolumn{7}{|c|}{ Emotional Functioning } \\
\hline & $\begin{array}{l}-0.019 \\
(n=266) \\
p=0.75\end{array}$ & $\begin{array}{l}0.050 \\
(n=274) \\
p=0.41\end{array}$ & $\begin{array}{l}0.128 \\
(n=266) \\
p=0.036\end{array}$ & $\begin{array}{l}0.153 \\
(n=274) \\
p=0.011\end{array}$ & $\begin{array}{l}0.294 \\
(n=262) \\
p<0.001\end{array}$ & $\begin{array}{l}0.432 \\
(n=267) \\
p<0.001\end{array}$ \\
\hline \multicolumn{7}{|c|}{ Social Functioning } \\
\hline & $\begin{array}{l}-0.062 \\
(n=266) \\
p=0.31\end{array}$ & $\begin{array}{l}0.033 \\
(n=274) \\
p=0.59\end{array}$ & $\begin{array}{l}0.107 \\
(n=266) \\
p=0.08\end{array}$ & $\begin{array}{l}0.097 \\
(n=274) \\
p=0.11\end{array}$ & $\begin{array}{l}0.376 \\
(n=262) \\
p<0.001\end{array}$ & $\begin{array}{l}0.378 \\
(n=267) \\
p<0.001\end{array}$ \\
\hline \multicolumn{7}{|c|}{ Treatment Burden* } \\
\hline & $\begin{array}{l}0.004 \\
(n=247) \\
p=0.95\end{array}$ & $\begin{array}{l}0.061 \\
(n=247) \\
p=0.34\end{array}$ & $\begin{array}{l}0.154 \\
(n=247) \\
p=0.016\end{array}$ & $\begin{array}{l}-0.011 \\
(n=247) \\
p=0.86\end{array}$ & $\begin{array}{l}0.463 \\
(n=244) \\
p<0.001\end{array}$ & $\begin{array}{l}0.331 \\
(n=241) \\
p<0.001\end{array}$ \\
\hline
\end{tabular}

worsening respiratory symptoms were reflected in changes in mean QOL-B Respiratory Symptoms scores.

For each scale, MID estimates from two distribution-based methods and one anchor-based method (using the GRCQ as an anchor) were averaged to determine the final MID. The anchorbased MID estimates showed more variation between studies than was observed for the distribution-based estimates, and some anchor-based estimates also differed substantially from the

Table 6 Test-retest reliability: intraclass correlation coefficients between screening (day 14) and baseline (day 0) for QOL-B scores

\begin{tabular}{|c|c|c|c|c|}
\hline \multirow[b]{2}{*}{ QOL-B V.3.0 scale } & \multicolumn{2}{|c|}{ AIR-BX1 (N=266) } & \multicolumn{2}{|c|}{ AIR-BX2 (N=274) } \\
\hline & $\mathrm{n}^{*}$ & Intraclass correlation coefficient & $\mathrm{n}^{*}$ & Intraclass correlation coefficient \\
\hline Respiratory Symptoms & 266 & 0.85 & 268 & 0.82 \\
\hline Physical Functioning & 266 & 0.84 & 273 & 0.86 \\
\hline Vitality & 266 & 0.72 & 273 & 0.76 \\
\hline Role Functioning & 265 & 0.87 & 270 & 0.86 \\
\hline Health Perceptions & 266 & 0.79 & 272 & 0.74 \\
\hline Emotional Functioning & 266 & 0.79 & 273 & 0.80 \\
\hline Social Functioning & 266 & 0.77 & 270 & 0.84 \\
\hline Treatment Burdent & 222 & 0.78 & 220 & 0.74 \\
\hline
\end{tabular}


Table 7 MID Estimates for the QOL-B scales

\begin{tabular}{|c|c|c|c|c|c|}
\hline \multirow[b]{2}{*}{ QOL-B V.3.0 scale and method of estimating MID } & \multicolumn{2}{|c|}{ AIR-BX1 } & \multicolumn{2}{|c|}{ AIR-BX2 } & \multirow{2}{*}{$\begin{array}{l}\text { Final } \\
\text { MID* }\end{array}$} \\
\hline & MID & n & MID & n & \\
\hline Respiratory Symptoms & & & & & 8.0 \\
\hline Anchor-basedt & 6.7 & 56 & 11.4 & 77 & \\
\hline $1 / 2 \mathrm{SD} \ddagger$ & 8.0 & 266 & 7.7 & 274 & \\
\hline SEM§ & 7.7 & 266 & 8.2 & 274 & \\
\hline Physical Functioning & & & & & 10.0 \\
\hline Anchor-basedt & 8.7 & 61 & 11.3 & 53 & \\
\hline $1 / 2 \mathrm{SD} \ddagger$ & 10.1 & 266 & 9.9 & 274 & \\
\hline SEM§ & 8.4 & 266 & 8.6 & 274 & \\
\hline Vitality & & & & & 10.0 \\
\hline Anchor-based $t$ & 11.9 & 49 & 8.9 & 51 & \\
\hline $1 / 2 \mathrm{SD} \ddagger$ & 9.5 & 266 & 9.4 & 274 & \\
\hline SEM§ & 10.0 & 266 & 11.6 & 274 & \\
\hline Role Functioning & & & & & 8.0 \\
\hline Anchor-basedt & 11.8 & 49 & 0.0 & 34 & \\
\hline $1 / 2 \mathrm{SD} \ddagger$ & 8.6 & 266 & 8.2 & 274 & \\
\hline SEM§ & 10.0 & 266 & 10.1 & 274 & \\
\hline Health Perceptions & & & & & 8.0 \\
\hline Anchor-basedt & 7.6 & 50 & 3.6 & 58 & \\
\hline $1 / 2 \mathrm{SD} \ddagger$ & 8.2 & 266 & 7.9 & 274 & \\
\hline SEM§ & 9.8 & 266 & 10.1 & 274 & \\
\hline Emotional Functioning & & & & & 7.0 \\
\hline Anchor-based $t$ & 5.1 & 44 & 4.6 & 40 & \\
\hline $1 / 2 \mathrm{SD} \ddagger$ & 7.1 & 266 & 6.8 & 274 & \\
\hline SEM§ & 8.2 & 266 & 8.8 & 274 & \\
\hline Social Functioning & & & & & 9.0 \\
\hline Anchor-basedt & 10.3 & 37 & 2.0 & 33 & \\
\hline $1 / 2 \mathrm{SD} \ddagger$ & 7.8 & 266 & 7.3 & 274 & \\
\hline SEM§ & 12.6 & 266 & 13.3 & 274 & \\
\hline Treatment Burden & & & & & 9.0 \\
\hline Anchor-basedt & 6.9 & 37 & 5.9 & 45 & \\
\hline $1 / 2 \mathrm{SD} \ddagger$ & 9.8 & 247 & 10.0 & 232 & \\
\hline SEM§ & 11.3 & 247 & 11.6 & 232 & \\
\hline
\end{tabular}

distribution-based estimates. These findings illustrate the complexity of determining MIDs using an anchor-based method and suggest that the final MIDs for scales with large differences (e.g, Role or Social Functioning) should be used with caution.

Each QOL-B item had 4 possible answer categories; e.g., the item 'Have you been coughing during the day' could be answered by selecting 'a lot,' 'a moderate amount,' 'a little' or 'not at all.' A change of one answer category for any of the nine items on the Respiratory Symptoms scale corresponded to 3.7 points; e.g., changing from 'a lot' to a 'moderate amount' of coughing during the day increased the Respiratory Symptoms score by 3.7 points. Thus, meeting the 8.0 -point MID required an average overall improvement or worsening of 2.2 answer categories. The MID for the Physical Functioning scale was 10.0 points. Because a change of 1 answer category for any of 5 items on this scale corresponded to 6.7 points, meeting the Physical Functioning scale MID required an average overall improvement or worsening of 1.5 answer categories. For a group of patients to meet the MID for the other 6 scales required an average overall improvement or worsening of from 0.8 to 1.2 answer categories.
Limitations of other PRO or HRQoL measures that have been used in this patient population include minimal coverage of respiratory symptoms (Leicester Cough Questionnaire ${ }^{28}$; Chronic Respiratory Questionnaire ${ }^{29}$ (CRQ)), lengthy or variable recall intervals $\left(\mathrm{SGRQ}^{30}\right)$ and substantial response burden (some SGRQ and CRQ forms). The QOL-B is the first PRO for non-CF bronchiectasis developed according to the FDA guidance. $^{12}$

Some minor limitations to the QOL-B emerged from these analyses. In this study population, approximately one quarter of the patients had baseline scores of 100 on the Emotional Functioning scale, indicating that it would not be well suited to monitor improvements from baseline in a comparable study population. The discrepancies in MID values obtained by the different methods for some of the scales also suggest that MIDs should be reassessed in each population of patients in which this measure is used; this conclusion is in line with literature recommendations for using MID values. ${ }^{31}$ The lack of improvement on the QOL-B Respiratory Symptoms scale after treatment with AZLI is not considered a limitation of the measure, but more likely reflects the lack of clinical benefit of this treatment in this 
Figure 1 Change from baseline Quality of Life-Bronchiectasis (QOL-B) Respiratory Symptoms scores on the day of a protocol-defined exacerbation. A, AZLI-treated patients $(n=30)$. B, Placebo-treated patients $(n=30)$. Analysis included patients with QOL-B scores at baseline and at a study visit at which treatment was initiated with intravenous, inhaled, intramuscular or oral antibiotics for a protocol-defined exacerbation.

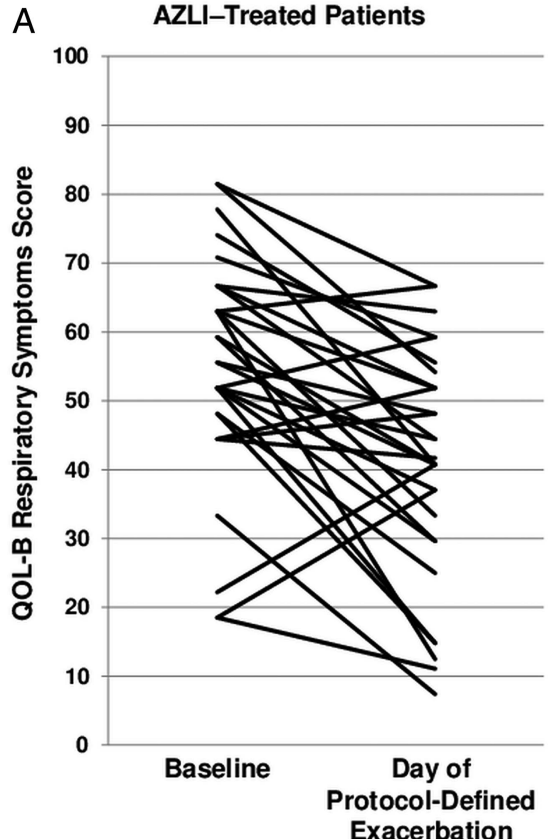

B Placebo-Treated Patients

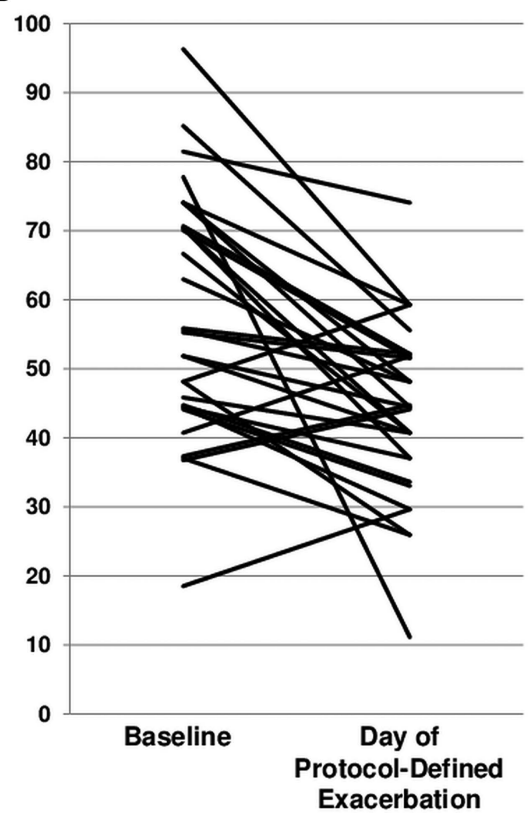

patient population. ${ }^{13}$ The analysis showing responsivity of the measure to protocol-defined exacerbations was exploratory in nature; it included only 60 of the 154 patients who had such exacerbations and did not take into account other changes in health status or QOL-B scores that may have occurred between baseline and the day of the exacerbation.

In conclusion, the QOL-B is a disease-specific questionnaire that measures symptoms, functioning and HRQoL relevant to patients with non-CF bronchiectasis. Content validity, reliability and responsivity have been established in a series of cognitive testing and interview studies and have been confirmed by the results of this final validation study. The QOL-B measure has been translated into more than 38 languages and is freely available $^{20}$ for use in clinical trials and routine clinical practice.

\section{Author affiliations}

${ }^{1}$ Department of Psychology \& Pediatrics, University of Miami, and Behavioral Health Sciences Research, Coral Gables, Florida, USA

${ }^{2}$ Division of Pulmonary, Critical Care \& Sleep Medicine, Department of Medicine, Georgetown University, Washington, District of Columbia, USA

${ }^{3}$ Division of Pulmonary, Allergy, Critical Care and Sleep Medicine, Department of Medicine, University of Miami, Miami, Florida, USA

${ }^{4}$ Gilead Sciences Inc., Seattle, Washington, USA

${ }^{5}$ Cardeas Pharma Corp., Seattle, Washington, USA

${ }^{6}$ Department of Medicine, Division of Pulmonary and Critical Care, Oregon Health \& Science University, Portland, Oregon, USA

Acknowledgements Medical writing assistance was provided by Kate Loughney, under the sponsorship of Gilead Sciences.

Contributors $A L Q, S A L, X L, A B M, T G O$ and $A F B$ were involved in the initial design of the studies. AFB was the lead investigator for AR-BX1 and AEO was the lead investigator for AIR-BX2. MAS was a clinical investigator. SAL and XL analysed the data. ALQ, SAL and TGO drafted the initial manuscript and all authors contributed to its development and approved the final version.

Funding The two clinical trials, AIR-BX1 (clinicaltrials.gov: NCT01313624) and AIR-BX2 (clinicaltrials.gov: NCT01314716), were sponsored by Gilead Sciences.

Competing interests ALQ: received consulting income from Gilead Sciences in relation to development of the QOL-B. AEO: received funding to Georgetown University for participation in the clinical trial. MAS: received funding to University of Miami for participation in the clinical trial. SAL: is an employee and stockholder of Gilead Sciences. XL: is an employee and stockholder of Gilead Sciences. ABM: was formerly an employee of Gilead Sciences and remains a stockholder. TGO: is an employee and stockholder of Gilead Sciences. AFB: received research funding from Gilead Sciences.

\section{Patient consent Obtained.}

Ethics approval Institutional Review Boards/Ethics Committees approved the study for each site.

Provenance and peer review Not commissioned; externally peer reviewed.

\section{REFERENCES}

1 O'Donnell AE. Bronchiectasis. Chest 2008;134:815-23.

2 Bilton D. Update on non-cystic fibrosis bronchiectasis. Curr Opin Pulm Med 2008; 14:595-9.

3 Tsang KW, Bilton D. Clinical challenges in managing bronchiectasis. Respirology 2009;14:637-50.

4 McShane PJ, Naureckas ET, Tino G, et al. Non-cystic fibrosis bronchiectasis. Am J Respir Crit Care Med 2013;188:647-56.

5 Sidhu MK, Mandal P, Hill AT. Bronchiectasis: an update on current pharmacotherapy and future perspectives. Expert Opin Pharmacother 2014;15:505-25.

6 Barker AF. Bronchiectasis. N Engl J Med 2002;346:1383-93.

7 Smith MP, Hill AT. Evaluating success of therapy for bronchiectasis: what end points to use? Clin Chest Med 2012;33:329-49.

8 Barker AF, Couch L, Fiel SB, et al. Tobramycin solution for inhalation reduces sputum Pseudomonas aeruginosa density in bronchiectasis. Am J Respir Crit Care Med 2000;162:481-5.

9 Haworth C, Foweraker J, Wilkinson P, et al. Inhaled colistin in patients with bronchiectasis and chronic Pseudomonas aeruginosa infection. Am J Respir Crit Care Med 2014;189:975-82.

10 Quittner AL, Marciel KK, Salathe MA, et al. A preliminary Quality of Life Questionnaire-Bronchiectasis: A patient-reported outcome measure for bronchiectasis. Chest 2014;146:437-48.

11 Olveira C, Olveira G, Espildora F, et al. Validation of a quality of life questionnaire for bronchiectasis: psychometric analyses of the Spanish QOL-B-V3.0. Qual Life Res 2014;23:1279-92.

12 US Food and Drug Administration. Guidance for industry. Patient-reported outcome measures: use in medical product development to support labeling claims. 2009. http://www.fda.gov/downloads/Drugs/Guidances/UCM193282.pdf

13 Barker AF, O'Donnell AE, Flume PA, et al. Aztreonam for Inhalation Solution (AZLI) in patients with non-CF bronchiectasis: the results from two randomized double-blind placebo-controlled Phase 3 trials. Lancet Respir Med 2014;2:738-49.

14 Wild D, Grove A, Martin M, et al. Principles of good practice for the translation and cultural adaptation process for Patient-Reported Outcomes (PRO) measures: report of the ISPOR task force for translation and cultural adaptation. Value Health 2005;8:94-104.

15 Acquadro C, Jambon B, Ellis D, et al. Language and translation issues. In: Spilker B, ed. Quality of life and pharmacoeconomics in clinical trials. 2nd edn. Philadelphia: Lippincott-Raven Publishers, 1996:575-85. 
16 American Thoracic Society. ATS statement: guidelines for the six-minute walk test. Am J Respir Crit Care Med 2002;166:111-17.

17 Euro Quality of Life-5 Dimensions (EQ-5D). http://www.euroqol.org/about-eq-5d.html

18 Wise RA, Brown CD. Minimal clinically important differences in the six-minute walk test and the incremental shuttle walking test. COPD 2005;2:125-9.

19 Puhan MA, Mador MJ, Held U, et al. Interpretation of treatment changes in 6-minute walk distance in patients with COPD. Eur Respir J 2008;32: $637-43$.

20 Quittner AL, Marciel KK, Barker AF. Quality of Life-Bronchiectasis. The measure is available without charge at: http://www.psy.miami.edu/gol b/

21 Ware J, Brook R, Williams K, et al. Conceptualization and measurement of health for adults in the health insurance study. Model of Health and Methodology. Rand Corporation. 1980;R-1987/1-HEW. http://www.rand.org/pubs/reports/2006/R1987.1.pdf

22 Landis JR, Koch GG. The measurement of observer agreement for categorical data. Biometrics 1977;33:159-74

23 Guyatt GH, Osoba D, Wu AW, et al. Methods to explain the clinical significance of health status measures. Mayo Clin Proc 2002;77:371-83.

24 Jaeschke R, Singer J, Guyatt GH. Measurement of health status. Ascertaining the minimal clinically important difference. Control Clin Trials 1989;10:407-15.
25 Wyrwich KW, Tierney WM, Wolinsky FD. Further evidence supporting an SEM-based criterion for identifying meaningful intra-individual changes in health-related quality of life. J Clin Epidemiol 1999;52:861-73.

26 Bilton D, Henig N, Morrissey B, et al. Addition of inhaled tobramycin to ciprofloxacin for acute exacerbations of Pseudomonas aeruginosa infection in adult bronchiectasis. Chest 2006;130:1503-10.

27 Lee AL, Button BM, Ellis S, et al. Clinical determinants of the 6-Minute Walk Test in bronchiectasis. Respir Med 2009;103:780-5.

28 Birring SS, Prudon B, Carr AJ, et al. Development of a symptom specific health status measure for patients with chronic cough: Leicester Cough Questionnaire (LCQ). Thorax 2003;58:339-43.

29 Guyatt GH, Berman LB, Townsend $M$, et al. A measure of quality of life for clinical trials in chronic lung disease. Thorax 1987;42:773-8.

30 Jones PW, Quirk FH, Baveystock CM, et al. A self-complete measure of health status for chronic airflow limitation: the Saint George's Respiratory Questionnaire. Am Rev of Respir Dis 1992;145:1321-7.

31 Revicki D, Hays RD, Cella D, et al. Recommended methods for determining responsiveness and minimally important differences for patient-reported outcomes. J Clin Epidemiol 2008:61:102-9. 